Pathophysiology

of Haemostasis and Thrombosis

\title{
Bothrojaracin, a Bothrops jararaca Snake Venom-Derived (Pro)Thrombin Inhibitor, as an Anti-Thrombotic Molecule
}

\author{
Russolina B. Zingali Marcos S. Ferreira Mariane Assafim Flávia S. Frattani
}

Robson Q. Monteiro

Instituto de Bioquímica Médica, CCS, Universidade Federal do Rio de Janeiro, Rio de Janeiro, Brazil

\section{Key Words}

Bothrojaracin · Snake venom • Anti-thrombotic effects • Thrombin · Prothrombin

\begin{abstract}
Bothrojaracin (BJC) is a selective and potent thrombin inhibitor $\left(K_{\mathrm{D}}=0.6 \mathrm{n} M\right)$ which also binds to prothrombin on proexosite I $\left(K_{\mathrm{D}}=175 \mathrm{nM}\right)$. Incubation of $\mathrm{BJC}$ with human or rat plasma produced a band that co-migrates with purified prothrombin-BJC complex. We further analyzed the in vivo anti-thrombotic effect of $B J C$ on a venous thrombosis model in rats that combines stasis and hypercoagulability. The administration of $1 \mathrm{mg} / \mathrm{kg}$ (i.v.) doses of BJC decreased thrombus weight by $\sim 95 \%$. Evaluation of the in vivo effect of BJC in mice using a pulmonary thromboembolism model induced by thrombin showed that BJC protects $100 \%$ of mice from death. Altogether, our data show that BJC is a potent antithrombotic agent that could further help the development of new prothrombin-directed drugs.
\end{abstract}

Copyright (c) 2005 S. Karger AG, Basel

\section{Introduction}

Venoms from different species of snakes contain components, mainly proteins and peptides, which interfere in various physiopathological processes, including neurotransmission, growth and metastasis of tumoural cells, inflammation, immune responses, cell growth, apoptosis and haemostasis [1]. A large variety of active principles that interfere in one or more physiological process have been isolated and their mechanism of action characterized $[2,3]$.

Bothrojaracin (BJC) is one of those proteins and it was described in 1993 as the first specific thrombin inhibitor isolated from the Bothrops jararaca snake venom [4]. Since then its structure and mechanism of action has been studied and characterized by our group and that of Dr. C. Bon (Pasteur Institute, France) [5].

\section{Structural Features}

$\mathrm{BJC}$ is a $27-\mathrm{kDa}$ protein with an acidic $\mathrm{pH}$ of 4.2 , formed by two distinct chains linked together by a single disulfide bridge [4]. Determination of its full amino-acid sequence (deduced from cDNA) showed that BJC is a member of the C-type lectin-like family [5]. BJC chains (A and B) are encoded by two distinct mRNAs showing high degree of homology between each other and to a large number of molecules isolated from snake venoms: botrocetin ( 80 and $60 \%$ homology to chains $\mathrm{A}$ and $\mathrm{B}$, respectively); factors IX/X-binding protein (57 and 54\%); GP Ib-binding protein (65 and 62\%); and salmorin (56 and $52 \%)$, among others [6-9].

As seen for other C-type lectin-like proteins, BJC displays only 11 out of the 13 amino-acid residues that constitute the Carbohydrate Recognition Domain (CRD), being unable to bind to carbohydrates [5]. In addition,

\section{KARGER}

Fax +4161306 1234

E-Mail karger@karger.ch

www.karger.com
C 2005 S. Karger AG, Basel

$1424-8832 / 05 / 0345-0160 \$ 22.00 / 0$

Accessible online at:

www.karger.com/pht
Dr. Russolina B. Zingali

Av Trompovski s/n CCS, Instituto de Bioquímica Médica, Bloco H2 sala 03

Universidade Federal do Rio de Janeiro

21941-590 Rio de Janeiro (Brazil)

Tel. +55 212562 6782, Fax +55 212270 8647, E-Mail lzingali@bioqmed.ufrj.br 
analysis of $\mathrm{Ca}^{2+}$-binding sites found in other lectin-like proteins [10] strongly suggests that none of BJC subunits recognize this ion. In fact, $\mathrm{Ca}^{2+}$ ions are not required for BJC activity (unpublished data).

Bothrops jararaca as well as other Bothrops sp. produce a large number of BJC isoforms that differ in their primary sequence [11-14]. These data reveal that there is a family of BJC-like molecules, isoforms that are present in the venom of all Bothrops sp. studied so far. Interestingly, common epitopes are also shared with high-molecularweight lectin-like molecules such as convulxin [15].

\section{Mechanism of Action}

BJC interacts with thrombin, forming a stable 1:1 complex, with an estimated $K_{\mathrm{D}}$ for immobilized BJC of $0.6 \mathrm{n} M[4,16]$. Competition assays showed that BJC displaces thrombin ligands such as fibrin, hirudin and thrombomodulin, indicating that it interacts with thrombin through the so-called thrombin binding exosite I. In addition, BJC inhibits the activation of factor V by thrombin, and is therefore a potent inhibitor of the feedback activation of the clotting cascade [17]. BJC may also bind to $\gamma$-thrombin, a proteolytic derivative of $\alpha$-thrombin that lacks exosite I. This interaction, that shows a 10 -fold lower affinity, is disrupted by heparin indicating that it is mediated by thrombin exosite II [16].

Remarkably, the catalytic activity of thrombin towards chromogenic substrates is not inhibited by BJC [4]. In fact, fluorescence assays showed that this protein produces distinct structural changes in the thrombin catalytic site, depending on whether it interacts with exosite I or exosite II [18]. Thus, BJC enhances $\alpha$-thrombin activity towards some chromogenic substrates, while it decreases the hydrolysis of the same substrates by $\gamma$-thrombin.

Moreover, BJC can also displace the thrombin that is bound to the clot and also can inhibit its clotting activity, suggesting that it may be an important tool to impair growth of thrombi [16].

BJC can also bind with high specificity to the thrombin zymogen prothrombin $[16,19,20]$. It binds to prothrombin with a $K_{\mathrm{D}}$ of $175 \mathrm{n} M$, indicating a $\sim 100$-fold lower binding affinity than that found for thrombin. Peptides based on the $\mathrm{C}$-terminal of hirudin have been also shown to bind prothrombin with $\sim 100$-fold lower affinities when compared to thrombin [21]. Actually, BJC competes with Hirudin $^{54-65}$ for binding to prothrombin [22], demonstrating that both molecules bind to the so-called proexosite I of prothrombin [21].

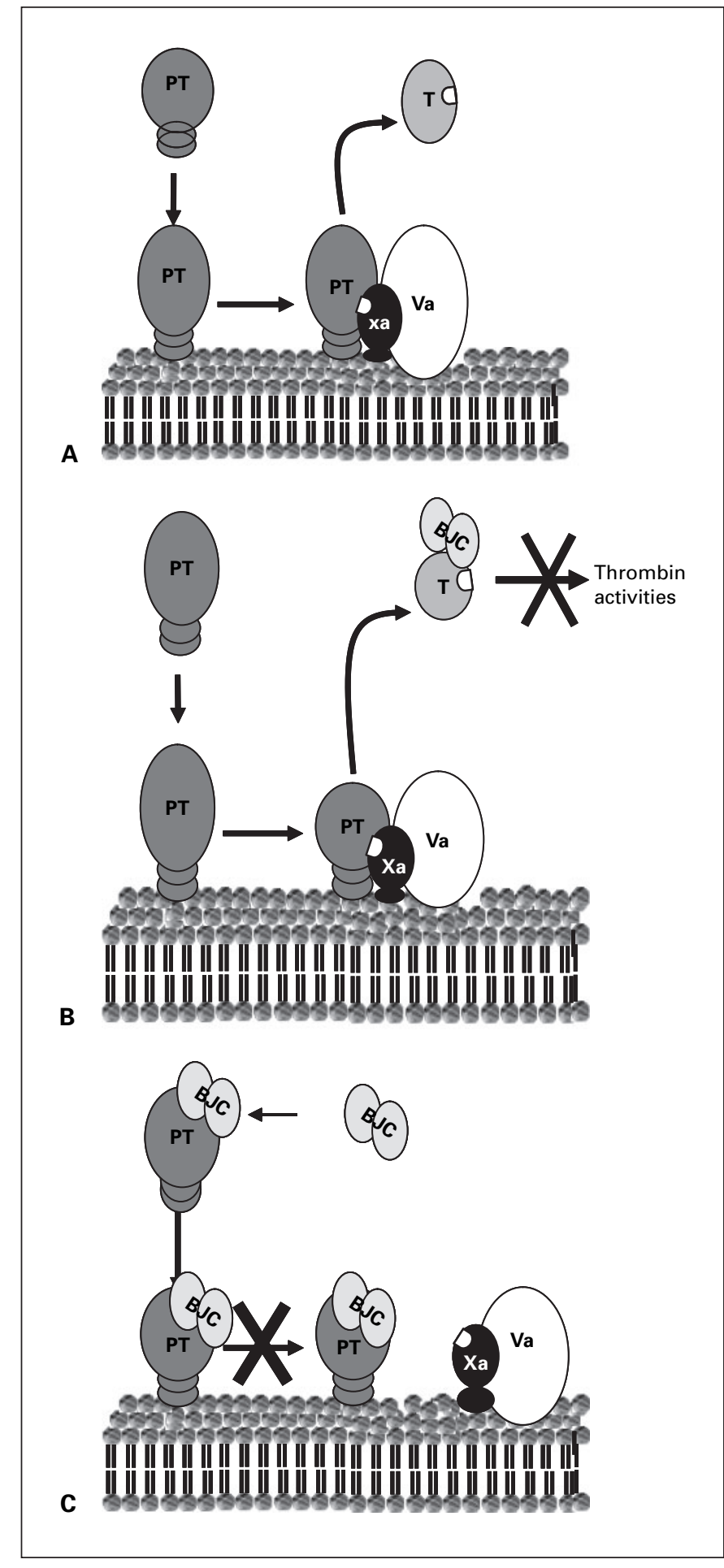

Fig. 1. Anti-coagulant mechanism of BJC. A Formation of regular prothrombinase complex. B Mechanism 1 of $\mathrm{BJC}$ inhibition is based on its binding to thrombin exosite-I and consequent inhibition of its activities. C Mechanism 2 is based on the inhibition of prothrombin activation through interaction with proexosite I. $\mathrm{BJC}=$ Bothrojaracin; $\mathrm{PT}=$ prothrombin; $\mathrm{Va}=$ activated factor $\mathrm{V}$; $\mathrm{Xa}=$ activated factor $\mathrm{X} ; \mathrm{T}=$ thrombin.

Pathophysiol Haemost Thromb 2005;34:160-163 
Table 1. Effects of bothrojaracin in vivo

\begin{tabular}{lll}
\hline Experiments, doses $1 \mathrm{mg} / \mathrm{kg}$ & Animals & Effects \\
\hline Deep venous thrombosis, in vivo & Wistar rats weighing $\sim 160 \mathrm{~g}(\mathrm{n}=3)$ & $95 \%$ inhibition \\
Clotting effect $-\mathrm{PT}$, ex vivo $^{\mathrm{b}}$ & Wistar rats weighing $\sim 160 \mathrm{~g}(\mathrm{n}=5)$ & 1.7 -fold over control \\
Clotting effect - aPTT, ex vivo $^{\mathrm{b}}$ & Wistar rats weighing $\sim 160 \mathrm{~g}(\mathrm{n}=5)$ & 1.5 -fold over control \\
Hemorrhagic effect, in vivo $^{\mathrm{c}}$ & Wistar rats weighing $\sim 160 \mathrm{~g}(\mathrm{n}=5)$ & 6.0 -fold over control \\
Thromboembolism, in vivo $^{\mathrm{d}}$ & Balb-C mice weighing $20 \mathrm{~g}(\mathrm{n}=15)$ & $100 \%$ protection \\
\hline
\end{tabular}

\footnotetext{
${ }^{a}$ Deep vein thrombosis model: Thrombus formation was induced by a combination of stasis and hypercoagulability at vena cava produced by intravenous administration of thromboplastin. After 20 min the formed thrombus was detached from the segment, dried for $1 \mathrm{~h}$ at $60^{\circ} \mathrm{C}$ and weighed. Bothrojaracin was administered $5 \mathrm{~min}$ before thrombogenic stimulus.

${ }^{\mathrm{b}}$ Ex vivo determination of APTT and PT: For APTT tests, cephalin plus kaolin (APTT reagent) were incubated for 1 min with $50 \mu 1$ of plasma $\left(37^{\circ} \mathrm{C}\right)$. The reaction was started by addition of $100 \mu \mathrm{l}$ of $\mathrm{CaCl}_{2}(25 \mathrm{mM})$. For PT tests, $50 \mu \mathrm{l}$ of plasma were incubated for $2 \mathrm{~min}\left(37^{\circ} \mathrm{C}\right)$. The reaction was started by addition of $100 \mu \mathrm{l}$ of thromboplastin with calcium (PT reagent).

${ }^{\mathrm{c}}$ Rat tail-transection model: For evaluation of the bleeding effect, the carotid artery was exposed and dissected. Bothrojaracin was administered through silicone tubing inserted into the carotid artery. Immediately 5 min after bothrojaracin administration the rat's tail was cut $3 \mathrm{~mm}$ from the tip. Blood loss was evaluated $120 \mathrm{~min}$ later as a function of absorbance at $540 \mathrm{~nm}$ due to the hemoglobin content in water solution.

d Thromboembolism model: Thrombotic event was induced by human thrombin $(2,000 \mathrm{IU} / \mathrm{kg}$ animal), and the survival rate was evaluated $15 \mathrm{~min}$ after thrombotic event. Bothrojaracin was injected i.v. at retro-orbital venous plexus 60 min before the thrombogenic stimulus. Results shown represent 3 groups of 5 animals each.
}

Formation of the BJC-prothrombin complex is particularly effective in preventing thrombin formation catalyzed by Oxyuranus scutellatus venom [20], which contains a highly active prothrombin activator structurally related to $\mathrm{FXa} / \mathrm{FVa}[23]$. We have also demonstrated that prothrombin activation by the prothrombinase complex is decreased in the presence of either BJC or Hirudin $^{54-65}$. This effect was much more evident in the presence of factor $\mathrm{Va}$ and activated platelets, suggestive of a physiological role for proexosite I [24].

Altogether, we have concluded that BJC exerts its anticoagulant effect by two distinct mechanisms (fig. 1): it binds to activated thrombin through exosite 1, blocking fibrinogen clotting, platelet activation, factor $\mathrm{V}$ activation and other effects, and it interacts with prothrombin, decreasing its proteolytic activation - especially in the presence of factor $\mathrm{Va}[19,20,24]$. These characteristics make BJC a promising tool for the investigation of anti-thrombotic activities in vivo.

\section{In vivo Effects of Bothrojaracin}

We have analyzed the in vivo anti-thrombotic effects of BJC in rats by using a venous thrombosis model that combines stasis and hypercoagulability. Thromboplastin
$(3 \mathrm{mg} / \mathrm{kg}$ ) was injected into the vena cava (below the distal loose suture) and stasis was immediately established, after $20 \mathrm{~min}$ the thrombus was removed. The formed detached thrombus was blotted on filter paper, dried, and weighed $(8.1 \pm 0.8 \mathrm{mg})$. Intravenous administration of BJC $(1 \mathrm{mg} / \mathrm{kg}), 5 \mathrm{~min}$ before thrombosis induction, caused a significant decrease of $\sim 95 \%$ in thrombus weight. The same dose of BJC conferred 100\% protection against thrombin-induced mortality in mice, on a pulmonary thromboembolism model (see table 1 for references). On the other hand, BJC produced an important increase in the bleeding effect in rats (tail-transection model), although with very little changes on ex vivo clotting times (aPTT and PT; table 1).

Compared to other anti-thrombotic drugs such as heparin [25] or glycyrrhizin [26], BJC shows a prolonged effect. In fact we have evidence that BJC remains in the plasma bound to prothrombin for at least for $12 \mathrm{~h}$ in vivo (unpublished results). Altogether, our data show that BJC is a potent anti-thrombotic agent and may be useful for the development of new drugs directed to both prothrombin and thrombin. On the other hand, prothrombin concentration in plasma $(100-150 \mathrm{mg} / \mathrm{ml})$ is very high when compared to other clotting factors. This is a possible limiting issue for the use of prothrombin inhibitors. Even though, efficacy and pharmacokinetics studies will be im- 
portant in order to determine which pathological state might be treated and/or prevented with anti-thrombotic drugs displaying this particular mechanism of action.

\section{Conclusion}

Although the mechanism of action of BJC is known in considerable detail, the structure-function relationship is yet to be understood. The structure of BJC complexed with prothrombin and thrombin will certainly furnish the necessary information that is missing today and which is necessary to understand why and how BJC binds to thrombin and prothrombin. This is a crucial issue to understand prior to use of this molecule as a prototype for the development of new drugs that can bind to zymogens such as prothrombin.

\section{Acknowledgements}

Authors thank Dr. Martha Sorenson (UFRJ, Brazil) for discussions and critical reading of the manuscript and Dione M. Silva for her technical assistance. Financial support has been given by $\mathrm{CNPq}$, FUJB, FAPERJ and IFS contract F 3156-1.

\section{References}

1 Stocker KF (ed): Medical Use of Snake Venom Proteins. Boca Raton, USA, CRC Press, 1990, p 272.

2 Markland FS: Snake venoms and the hemostatic system. Toxicon 1998;36:1749-1800.

3 Braud S, Bon C, Wisner A: Snake venom proteins acting on hemostasis. Biochimie 2000;82: 851-859.

-4 Zingali RB, Jandrot-Perrus M, Guillin MC, Bon C: Bothrojaracin, a new thrombin inhibitor isolated from Bothrops jararaca venom: characterization and mechanism of thrombin inhibition. Biochemistry 1993;32:1079410802.

5 Arocas V, Castro HC, Zingali RB, Guillin MC, Jandrot-Perrus M, Bon C, Wisner A: Molecular cloning and expression of bothrojaracin, a potent thrombin inhibitor from snake venom. Eur J Biochem 1997;248:550-557.

-6 Usami Y, Fujimura Y, Suzuki M, Ozeki Y, Nishio K, Fukui H, Titani K: Primary structure of two-chain botrocetin, a von Willebrand factor modulator purified from the venom of Bothrops jararaca. Proc Natl Acad Sci USA 1993; 90:928-932.

7 Sekiya F, Atoda H, Morita T: Isolation and characterization of an anticoagulant protein homologous to botrocetin from the venom of Bothrops jararaca. Biochemistry 1993;32: 6892-6897.

-8 Kawasaki T, Fujimura Y, Usami Y, Suzuki M, Miura S, Sakurai Y, Makita K, Taniuchi Y, Hirano K, Titani K: Complete amino acid sequence and identification of the platelet glycoprotein Ib-binding site of jararaca GPIb-BP, a snake venom protein isolated from Bothrops jararaca. J Biol Chem 1996;271:1063510639.

9 Koh Y, Chung K, Kim D: Purification and cDNA cloning of salmorin that inhibits fibrinogen clotting. Thromb Res 2000;99:389-398.

10 Atoda H, Kaneko H, Mizuno H, Morita T: Calcium-binding analysis and molecular modeling reveal Echis coagulation factor IX/factor $\mathrm{X}$-binding protein has the Ca-binding proper- ties and Ca ion-independent folding of other $>20$ Monteiro RQ, Zingali RB: Inhibition of proC-type lectin-like proteins. FEBS Lett 2002; 531:229-234.

11 Monteiro RQ, Carlini CR, Guimarães JA, Zingali RB: Distinct bothojaracin isoforms produced by individual jararaca (Bothrops jararaca) snakes. Toxicon 1997;35:649-657.

12 Monteiro RQ, Dutra DLS, Machado OLT, Carlini CR, Guimarães JA, Bon C, Zingali RB: Bothrops jararaca snakes produce several bothrojaracin isoforms following an individual pattern. Comp Biochem Physiol B 1998;120: 791-798.

13 Castro HC, Dutra DLS, Oliveira-Carvalho AL, Zingali RB: Bothroalternin, a thrombin inhibitor from the venom of Bothrops alternatus. Toxicon 1998;36:1903-1912.

14 Castro HC, Fernandes M, Zingali RB: Identification of bothrojaracin-like proteins in snake venoms from Bothrops species and Lachesis muta. Toxicon 1999;37:1403-1416.

15 Castro HC, Lemos MG, Bon C, Zingali RB: Comparative evaluation of immunological and structural similarities of snake venom Ctype lectin proteins. Toxicon 2003;41:525528.

16 Arocas V, Zingali RB, Guillin MC, Bon C, Jandrot-Perus M: Bothrojaracin: a potent two-sitedirected thrombin inhibitor. Biochemistry 1996;35:9083-9089.

17 Arocas V, Lemaire C, Bouton MC, Beazeaud A, Bon C, Guillin MC, Jandrot-Perrus M: Inhibition of thrombin-catalysed factor $\mathrm{V}$ activation by bothrojaracin. Thromb Haemost 1998 ; 79:1157-1161.

18 Monteiro RQ, Rapôso JG, Wisner A, Guimarães JA, Bon C, Zingali RB: Allosteric changes of thrombin catalytic site induced by interaction of bothrojaracin with anion-binding exosities I and II. Biochem Biophys Res Commun 1999;262:819-822.

19 Zingali RB, Bianconi ML, Monteiro RQ: Interaction of bothrojaracin with prothrombin Haemostasis 2001;31:273-278. thrombin activation by bothrojaracin, a Ctype lectin from Bothrops jararaca venom. Arch Biochem Biophys 2000;382:123-128.

21 Anderson PJ, Nesset A, Dharmawardana KR, Bock PE: Role of proexosite I in factor Va-dependent substrate interactions of prothrombin activation. J Biol Chem 2000;275:1643516442.

22 Monteiro RQ, Bock PE, Bianconi ML, Zingali RB: Characterization of bothrojaracin interaction with human prothrombin. Protein Sci

23 Speijer H, Govers-Riemslag JW, Zwaal RF, Rosing J: Prothrombin activation by an activator from the venom of Oxyuranus scutellatus (Taipan snake). J Biol Chem 1986;261:1325813267.

24 Monteiro RQ, Zingali RB: Bothrojaracin, a proexosite I ligand, inhibits factor Va-accelerated prothrombin activation. Thromb Haemost 2002;87:288-293.

25 Hirsh J, Warkentin TE, Shaughnessy SG, Anand SS, Halperin JL, Raschke R, Granger C, Ohman EM, Dalem JE: Heparin and low molecular weight heparin: mechanism of action, pharmacokinetics, dosing, monitoring, efficacy and safety. Chest 2001;119:64S-94S.

-26 Mendes-Silva W, Assafim M, Ruta B, Monteiro RQ, Guimarães JA, Zingali RB: Antithrombotic effect of Glycyrrhizin, a plant-derived thrombin inhibitor. Thromb Res 2003; 112:93-98

27 Herbert JM, Hérault JP, Bernat A, Van Amsterdan RGM, Vogel GMT, Lormeau JC: Biochemical and pharmacological properties of SANORG 32701. Comparison with the 'synthetic pentasacharide (SR90107/org 31549)' and standard heparin. Circ Res 1996;79:590600 .

-28 Gresele P, Momi S, Berrettini M, Nenci GG, Schwarz HP, Semeraro N, Colluci M: Activated human protein $\mathrm{C}$ prevents thrombin-induced thromboembolism in mice. J Clin Invest 1998;101:667-676. 2001;10:1897-1904. 